\title{
Clinical Cure of a Thrombus of Right Heart Cavities with Streptokinase. Importance of Echocardiography in the Urgent Diagnosis
}

\begin{abstract}
Traore-Kissima Abdoulaye ${ }^{1}$, Doumbia Modibo ${ }^{1}$, Haidara Ousmane $^{1}$, Traore Ousmane $^{1}$, Kassogue Oumar ${ }^{1}$, Sanogo B Drissa ${ }^{1}$, Traore Salia ${ }^{1}$, Kane Adama ${ }^{2}$ and Cenac Arnaud ${ }^{3 *}$
\end{abstract}

${ }^{1}$ Department of Cardiology, Sikasso Hospital, Mali

${ }^{2}$ Gaston Berger University of Saint Louis, Senegal

${ }^{3}$ Faculty of Medicine of Brest, University of Western Brittany, France

*Corresponding author: Cenac Arnaud, Faculty of Medicine of Brest, University of

Western Brittany, Brest, France.

Received Date: August 11, 2020

Published Date: August 26, 2020

\begin{abstract}
At Sikasso hospital (Mali), the authors report a case of severe pulmonary embolism with the presence of voluminous thrombus in the right heart cavities. Echocardiography rapidly demonstrated the presence of right intracardiac thrombus. Thrombolysis by streptokinase, immediately performed, resulted in clinical healing. Clinical cure of a thrombus of right heart cavities with streptokinase. Importance of echocardiography in the urgent diagnosis.
\end{abstract}

Keywords: Pulmonary embolism; Thrombolysis; Echocardiography; Sikasso; Mali

\section{Introduction}

A pulmonary embolism is severe when signs of hemodynamic instability is associated with dyspnea and tachycardia. The demonstration of a large thrombus in the right cardiac chambers allows to affirm that the vital prognosis is started in the short term [1]. Current imaging techniques (computed tomography, magnetic resonance imaging) make it possible to visualize the thrombus [2,3]. These techniques must still be available in urgent reception centers. We report the clinical case of a severe pulmonary embolism, the diagnosis of which was made by echocardiography, in the absence of other imaging techniques.

\section{Case Report}

A 46-year-old black African man, breeding engineer, presents to the cardiology emergency department at Sikasso hospital (Mali).
The symptoms are dyspnea (NYHA III) and right basic thoracic pain with dry cough.

Interrogation of the patient reveals a brief loss of consciousness (syncope?) before arrival at the hospital. Antecedents are arterial hypertension, diabetes mellitus type II, smoking (10 packagesyear). The patient's medical follow-up is irregular. At examination, asthenia, dyspnea on slightest effort, profuse sweats, cold limb ends, spontaneous turgor of the jugular veins are noted. The calves are flexible and painless. The body mass index is 20 . Blood pressure is $80 / 50 \mathrm{~mm} \mathrm{Hg}$. The breath rate is $32 / \mathrm{mn}$, cardiac rate $110 / \mathrm{mn}$ and arterial saturation $60 \%$. At cardiac auscultation, the second heart sound is reduplication at pulmonary area. Peripheral pulses are weakly palpable. At pleuropulmonary examination, the 
thoracic base is silent. Initial biological results = positive D-dimer, creatininaemia $=10 \mathrm{mg} / \mathrm{L}$, spontaneous INR (International Normalized Ratio) $=1.82$, hemoglobin level $=13.4 \mathrm{~g} / \mathrm{dL}$, no hyperleukocytosis, transaminases are normal values.

An emergency transthoracic echocardiography is performed (Hitachi EUB 5500 color Doppler, pulse and continuous Doppler and tissue Doppler; probes: 10-5 MHZ, 4-2 MHZ, 5-2 MHZ): it allows to visualize the presence of a voluminous free thrombus in the right atrium (Figure 1), extended to the pulmonary trunk, a paradoxical movement of the septum, a dilated and hypokinetic right ventricular cavity, an impaired systolic function with TAPSE (Tricuspid Annulus Plane Systolic Excursion) $=13 \mathrm{~mm}$, (normal $>18 \mathrm{~mm}$ ). Pulmonary arterial hypertension is present with a right ventricle-right atrium gradient $=59+10 \mathrm{~mm} \mathrm{Hg}$. The diagnosis of pulmonary embolism is made, severe, because the association of hemodynamic instability and large intracardiac thrombus. Thrombolysis with streptokinase is started: 1.5 million IU given over 2 hours + low molecular-weight heparin then vitamin $\mathrm{K}$ antagonist (fluindione, $20 \mathrm{mg}$ per day with esomeprazole, $40 \mathrm{mg}$ per day). The clinical course is immediately favorable: at day +2 after thrombolysis, hemodynamic is stable and the image of thrombus has disappeared.

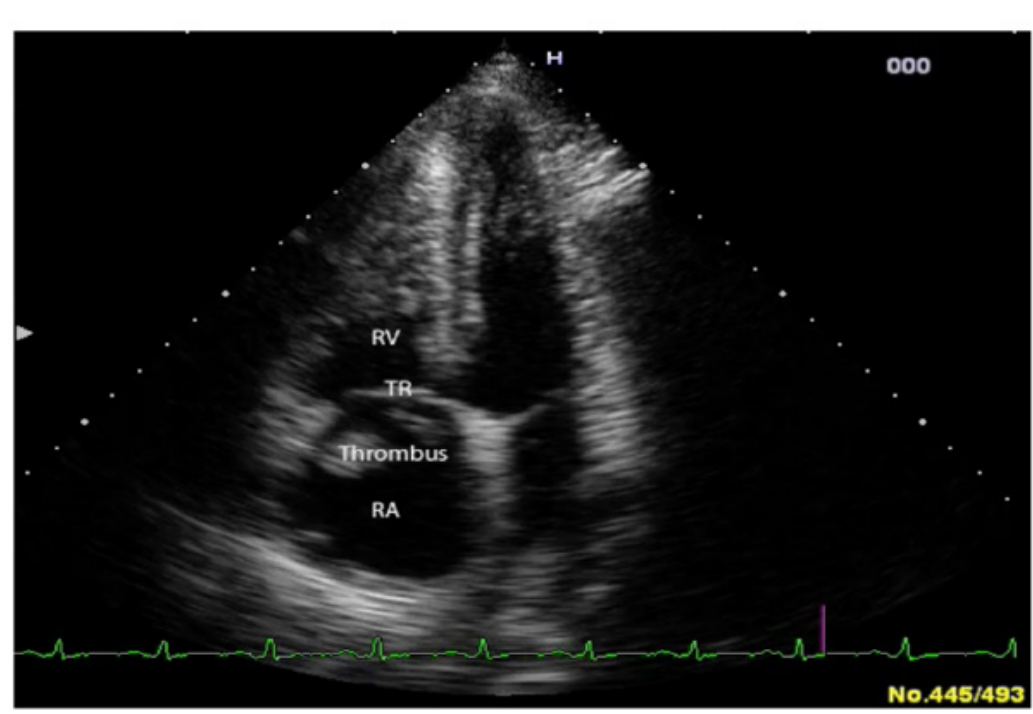

Figure 1: Apical slide of the 4 cavities. Picture of the thrombus in the right atrium. RA: right atrium, RV: right ventricle, TR: tricuspid valve.

\section{Discussion}

Clinical, biological, and echocardiographic signs are those of a severe pulmonary embolism with right intracardiac thrombus [1, 2]. The presence of signs of shock attests that the immediate vital prognosis is threatened [3]. The rapidly favorable clinical outcome with streptokinase is made possible by the performance of the echocardiography. Direct visualization of the right intracardiac thrombus imposed the diagnosis and allowed immediate therapeutic decision making. Venous thromboembolic disease is quite rare in black Africa in 1974 [4]. Today, pulmonary embolism is quite common as recent publications indicate [5-7]. The training of physicians must take this fact into account. In addition, diagnostic and therapeutic means must be made available to them.

\section{Acknowledgement}

None.

\section{Conflict of Interest}

No conflict of interest.

\section{References}

1. Konstantinides S, Torbicki A, Agnelli G, Danchin N, Fitzmaurice D, et al. (2014) 2014 ESC Guidelines on the diagnosis and management of acute pulmonary embolism. Eur Heart J 35: 3033-3369.

2. Chartier L, Michon P, Loubeyre C, Asseman P, Bérégi P, et al. (1997) Mobile thrombi of the right heart in pulmonary embolism. Arch Mal Coeur Vaiss 90(11): 1471-1416.

3. Philippot Q, Roche A, Goyard C, Pastré J, Planquette B, et al. (2018) Management of Massive Pulmonary Embolism in the Intensive Care Unit. Méd Intensive Réa 27: 443-451.

4. Williams AO (1974) Pulmonary embolism. In Cardiovascular disease in the tropics. Shaper AG, Hutt MS, Fejfar Z (eds.), Lavenham Press, London pp. 314-323.

5. Diali Ib, Coulibaly S, Minta I, Ba Ho, Diakite M, et al. (2011) Cases, signs, and outcome of 30 patients with pulmonary embolus. Mali Med 26(1): 3-6.

6. Pessinaba S, Atti YDM, Baragou S, Pio M, Afassinou Y, et al. (2017) Pulmonary embolism at the University Hospital Campus of Lome (Togo): a retrospective study about 51 cases. Pan African Medical Journal (open access) 27: 129 .

7. Seghda TAA, Yaméogo NV, Millogo GRC, Kagambega L, Kologo J, et al. (2019) Management and prognosis of pulmonary embolism associated with right heart thrombi: a prospective study at the University Hospital Yalgado Ouédraogo. Ann Cardiol Angeiol (Paris) 68(2): 65-70. 